Virginia Commonwealth University

vCU Scholars Compass

2009

\title{
One parameter control of the size of iron oxide nanoparticles synthesized in reverse micelles
}

\author{
M. D. Shultz \\ Virginia Commonwealth University \\ W. Braxton \\ Virginia State University \\ C. Taylor \\ Virginia State University \\ E. E. Carpenter \\ Virginia Commonwealth University, ecarpenter2@vcu.edu
}

Follow this and additional works at: http://scholarscompass.vcu.edu/chem_pubs

Part of the Chemistry Commons

Shultz, M. D., Braxton, W., \& Taylor, C., et al. One parameter control of the size of iron oxide nanoparticles synthesized in reverse micelles. Journal of Applied Physics, 105, 07A522 (2009). Copyright (C 2009 American Institute of Physics.

\section{Downloaded from}

http://scholarscompass.vcu.edu/chem_pubs/24

This Article is brought to you for free and open access by the Dept. of Chemistry at VCU Scholars Compass. It has been accepted for inclusion in Chemistry Publications by an authorized administrator of VCU Scholars Compass. For more information, please contact libcompass@vcu.edu. 


\title{
One parameter control of the size of iron oxide nanoparticles synthesized in reverse micelles
}

\author{
M. D. Shultz, ${ }^{1}$ W. Braxton, ${ }^{2}$ C. Taylor, ${ }^{2}$ and E. E. Carpenter ${ }^{1, a)}$ \\ ${ }^{1}$ Virginia Commonwealth University, Richmond, Virginia 23284, USA \\ ${ }^{2}$ Virginia State University, Petersburg, Virginia 23806, USA
}

(Presented 12 November 2008; received 18 September 2008; accepted 17 December 2008; published online 24 March 2009)

\begin{abstract}
Iron oxide nanoparticles were synthesized via reverse micelle methods. The initial iron concentration was varied, while maintaining all other parameters constant, in order to investigate the effect of the iron concentration on the resultant iron oxide nanoparticle size. Increasing the iron concentration from $0.125 \mathrm{M}$ to $0.5 \mathrm{M}$ yielded an increase in average nanoparticle diameter from 4.71 to $7.95 \mathrm{~nm}$, as measured by transmission electron microscopy. Three other concentrations between $0.125 \mathrm{M}$ and $0.5 \mathrm{M}$ showed corresponding size variations, all with statistical significance. Magnetic characterization by vibrating sample magnetometry and powder x-ray diffraction was performed to verify proper phase and material. Further insight into the reverse micelle method was acquired along with the ability to tune the nanoparticle size. (C) 2009 American Institute of Physics.
\end{abstract}

[DOI: $10.1063 / 1.3075983$ ]

Controlled synthesis of various sizes of nanoparticles is vital in nanotechnology since most desirable properties of nanoparticles depend on their dimensions. The use of reverse micelle systems to create isolated microreactor and nanoreactor in which the nanomaterials can be produced has been a leading method of choice in ferrite and many other magnetic material synthesis. ${ }^{1-5}$ A central composite design analysis in recent work involving nonylphenoxy poly(ethyleneoxy)ethanol (NP4 and NP7) and cyclohexane as the surfactant system has presented a chemometric model for adjusting the size of the reverse micelles. ${ }^{6}$ The hydrodynamic diameter of the reverse micelle is predicted by changing three initial variables of $r, \omega$, and [NP] according to the following equation:

$$
\begin{aligned}
\text { Size }= & 1.75( \pm 0.93)-3.4( \pm 1.4) r \omega+3.64( \pm 0.51) \omega \\
& -4.64( \pm 0.80) \omega[\mathrm{NP}] .
\end{aligned}
$$

In this equation, $r$ is the ratio of NP4 to total surfactant, $\omega$ is the mole ratio of water to total surfactant, and $[\mathrm{NP}]$ is the concentration of surfactant in the system. Although this model predicted the size of the reverse micelles formed, it was unable to affect the resultant size of the nanoparticle by varying these three parameters. ${ }^{6}$ This work utilizes a reverse micelle system of known hydrodynamic radius as determined by Eq. (1). Holding these parameters constant, the initial iron concentration was varied to investigate the ability to affect the resultant nanoparticle size with this one synthetic parameter.

Iron oxide nanoparticles were synthesized by the coprecipitation of $\mathrm{FeCl}_{2}$ and $\mathrm{FeCl}_{3}$ with ammonium hydroxide employing reverse micelle methods and Schlenk line techniques. ${ }^{4,7}$ Prior to performing the synthesis with varying iron concentrations, several syntheses were carried out to determine the optimal initial $\mathrm{Fe}^{3+} / \mathrm{Fe}^{2+}$ ratio that would yield

\footnotetext{
a) Author to whom correspondence should be addressed. Electronic mail: ecarpenter2@vcu.edu.
}

the most magnetic and crystalline material directly from the synthesis at room temperature. The reason for this was that most iron oxide samples prepared in a similar fashion are annealed postsynthesis for enhanced crystallinity, which could alter the size, morphology, and degree of aggregation. Thus to isolate the effect of the one synthesis parameter of interest, it was necessary to analyze all samples without annealing. Various syntheses were conducted while changing the initial $\mathrm{Fe}^{3+} / \mathrm{Fe}^{2+}$ ratio from $10 / 90$ to $90 / 10$. From these syntheses, it was determined that a $60 / 40$ mol ratio of $\mathrm{Fe}^{3+} / \mathrm{Fe}^{2+}$ was the best condition to work with, which yielded the strongest magnetic product directly from the synthesis at room temperature. Controlling this ratio in the initial precipitation steps was also necessary because other work in the literature has shown that the initial $\mathrm{Fe}^{3+} / \mathrm{Fe}^{2+}$ ratio affects the precipitation route, ${ }^{4}$ thereby influencing the crystallinity and structure of preannealed samples.

Another decision made, in order to elucidate the effect that the initial iron concentration would have on the size of a resultant nanoparticle, was in choosing one region in phase space to work with in producing the reverse micelles. With $r=0.25, \omega=6.08$, and $[\mathrm{NP}]=0.37$, Eq. (1) predicts the hydrodynamic reverse micelle diameter to be $8.35 \mathrm{~nm}$. The initial surfactant and cyclohexane used were degassed under $\mathrm{N}_{2}$ utilizing Schlenk line techniques to prevent initial oxidation and ensure that the proper starting ratio of $\mathrm{Fe}^{3+} / \mathrm{Fe}^{2+}$ was maintained. The aqueous iron solutions were quickly added to the surfactant and cyclohexane to form reverse micelles and held under $\mathrm{N}_{2}$. This was then added to another identical reverse micelle system containing concentrated ammonium hydroxide as the aqueous phase under $\mathrm{N}_{2}$. Then the precipitation reaction began and was allowed to continue for 30 $\min$. The reaction was quenched with an equal volume of methanol, and the particles were able to be magnetically separated, further washed with methanol, and dried under vacuum. Transmission electron microscopy (TEM) was uti- 


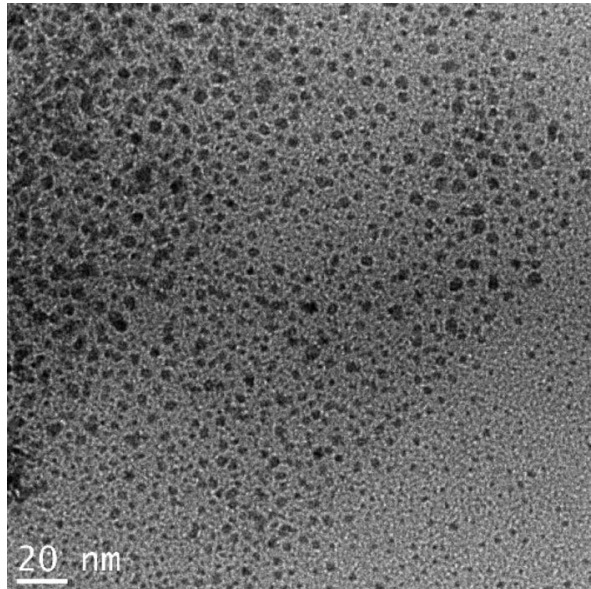

FIG. 1. TEM image of iron oxide nanoparticles synthesized with an initial iron concentration of $0.125 \mathrm{M}$.

lized to analyze the nanoparticle diameter and powder x-ray diffraction (XRD) was used to ensure that the spinel phase was achieved without other crystalline forms of iron oxide.

The TEM image in Fig. 1 shows the iron oxide nanoparticles synthesized with an initial iron concentration of $0.125 M$. As can be seen, the particles are roughly spherical, and though there was some variation in aggregation level between samples, Fig. 1 is representative of all samples in basic shape and appearance. Performing random measurements on three separate images per sample, it was found that using initial iron concentrations of $0.125 \mathrm{M}, 0.25 \mathrm{M}$, and $0.5 M$ yielded average diameters of $4.71 \pm 0.09,6.15 \pm 0.21$, and $7.95 \pm 0.30 \mathrm{~nm}$. These values of concentration correspond to $0.0005 \mathrm{~mol} \mathrm{Fe}, 0.001 \mathrm{~mol} \mathrm{Fe}$, and $0.002 \mathrm{~mol} \mathrm{Fe}$, respectively. Magnetic analysis via vibrating sample magnetometry (VSM) seen in Fig. 2 shows the maximum value of magnetization at $0.5 \mathrm{~T}$ to be $28.5 \mathrm{emu} / \mathrm{g}$ for the smallest particles $(0.0005 \mathrm{~mol} \mathrm{Fe})$. In this case, as the particle size increases, the strength of the magnetic moment diminishes and begins to approach saturation more quickly. This magnetic dilution trend in the VSM data can partially be explained by analyzing data from XRD. Scherer analysis performed on five peaks of the XRD pattern yielded minimal

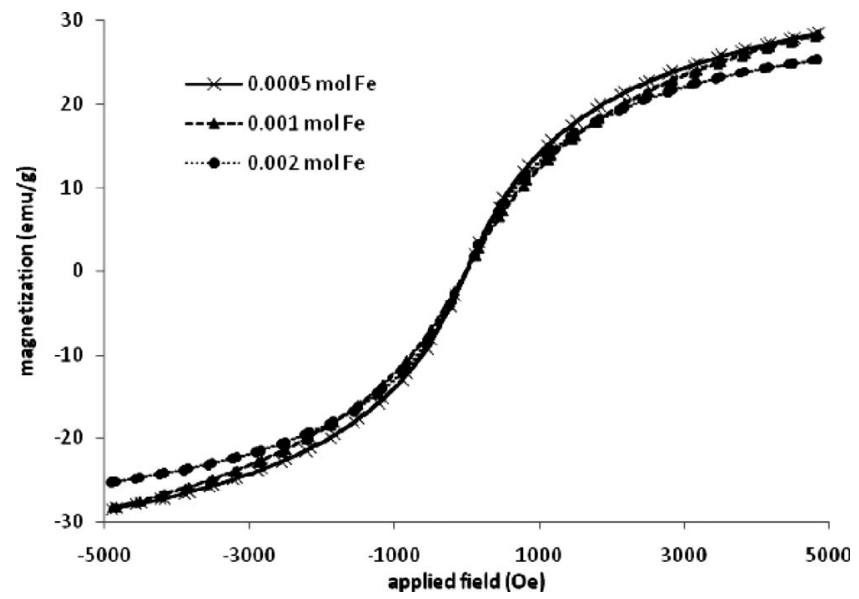

FIG. 2. VSM plot of magnetization vs applied field for iron oxide nanoparticles as synthesized.

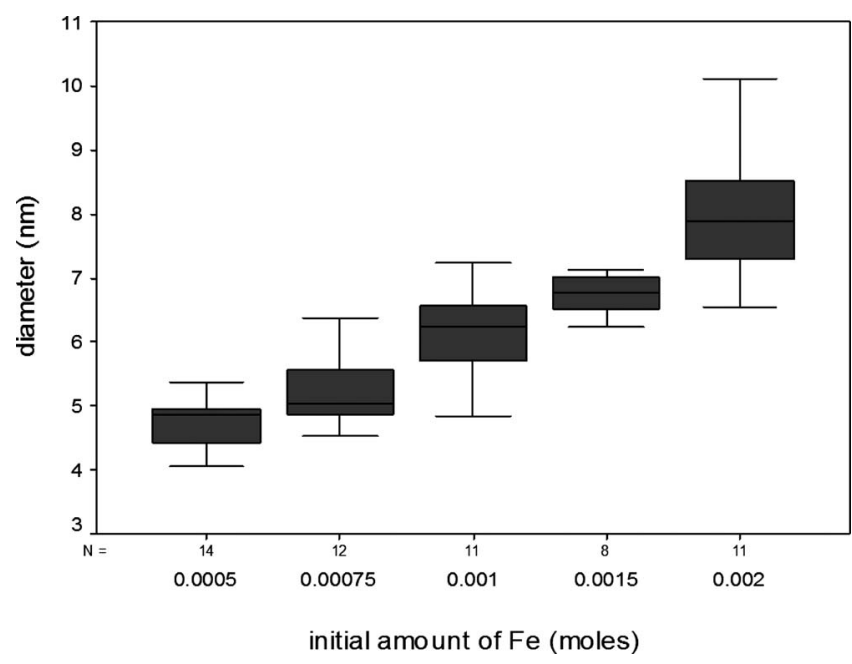

FIG. 3. Box plot of mean iron oxide nanoparticle diameter as measured by TEM.

increase in crystallite size of about $0.5 \mathrm{~nm}$. Therefore, the particle size increased greater than the crystalline region, thus diluting overall magnetic moment.

Theoretical size calculations based on density were performed that also corroborate the magnetic dilution and enhanced paramagnetic behavior. Using the $4.71 \mathrm{~nm}$ (from the synthesis with $0.0005 \mathrm{~mol} \mathrm{Fe}$ ) as a core size and assuming the density of maghemite $\left(4.9 \mathrm{~g} / \mathrm{cm}^{3}\right)$ for the core and subsequent shells, particle sizes were predicted to be $5.93 \mathrm{~nm}$ for $0.001 \mathrm{~mol} \mathrm{Fe}$ and $7.48 \mathrm{~nm}$ for $0.002 \mathrm{~mol} \mathrm{Fe}$. While these values are in decent agreement with the measured diameters of 6.15 and $7.94 \mathrm{~nm}$, this particle makeup should lead to increased magnetization. Now performing similar calculations starting with the same core size, but using a lower density for the subsequent shells (4.28=average density of goethite), particle sizes of 6.19 and $7.96 \mathrm{~nm}$ are predicted and in much better agreement with the measured values from TEM. The assumption of lower density shells on a maghemite core is in agreement with the XRD data showing little change in crystallite size. Also, amorphous packing on the surface would most likely be in the form of an iron oxyhydroxide such as $\mathrm{FeO}(\mathrm{OH})$, which would be less dense. The thicker amorphous layer also caused higher degrees of aggregation between particles, as was stated previously. This would lead to more interaction between particles, thereby exhibiting more ferrimagnetic character, as seen in Fig. 2 by the less steep approach toward saturation. The smaller particles, being more crystalline throughout and dispersed, as shown in Fig. 1, will have more superparamagnetic character, maintaining a higher slope with increasing field or not reaching saturation at all. This is indeed the trend seen in Fig. 2.

Further syntheses were performed using two intermediate values of initial $\mathrm{Fe}(0.00075 \mathrm{~mol} \mathrm{Fe}$ and $0.0015 \mathrm{~mol}$ $\mathrm{Fe}$ ), which resulted in the size trend seen in Fig. 3. Each of these values is different from the directly adjacent sample with statistical significance, $p<0.05$ (with the exception of the $0.00075 \mathrm{~mol} \mathrm{Fe}$ sample), thus showing that when the concentration was increased at set intervals, the average diameter increased accordingly. 
These results show promise in the area of nanoparticle size design with reverse micelles. The mechanism behind this size control is proposed to be more related to the number of micelles produced in a given system rather than the size of the micelle. In other words, the reverse micelles act to separate the starting materials into uniform small amounts. This then separates the nucleation events in a proportion to the number of micelles, followed by subsequent material exchange between reverse micelles and growth. This work could lead to further studies involving attempts to correlate and calculate the number of micelles formed to the resultant size of the nanoparticles but has clearly established some relative control of the size based on one synthetic parameter. Also, with the ability to adjust particle size and previous work in the literature showing cation occupancy variations based on initial synthetic parameters, ${ }^{4}$ two-point design and tailoring of mixed metal ferrites can be achieved.

${ }^{1}$ E. E. Carpenter, S. Calvin, R. M. Stroud, and V. G. Harris, Chem. Mater. 15, 3245 (2003).

${ }^{2}$ M. A. Willard, L. K. Kurihara, E. E. Carpenter, S. Calvin, and V. G. Harris, Int. Mater. Rev. 49, 125 (2004).

${ }^{3}$ S. A. Morrison, E. E. Carpenter, V. G. Harris, and C. A. Cahill, J. Nanosci. Nanotechnol. 5, 1323 (2005).

${ }^{4}$ M. D. Shultz, M. J. Allsbrook, and E. E. Carpenter, J. Appl. Phys. 101, 09M518 (2007).

${ }^{5}$ M. D. Shultz, S. Calvin, P. P. Fatouros, S. A. Morrison, and E. E. Carpenter, J. Magn. Magn. Mater. 311, 464 (2007).

${ }^{6}$ M. A. Michaels, S. Sherwood, M. Kidwell, M. J. Allsbrook, S. A. Morrison, S. C. Rutan, and E. E. Carpenter, J. Colloid Interface Sci. 311, 70 (2007).

${ }^{7}$ S. A. Morrison, C. L. Cahill, E. E. Carpenter, S. Calvin, R. Swaminathan, M. E. McHenry, and V. G. Harris, J. Appl. Phys. 95, 6392 (2004). 